\title{
Gestión de inventario. Relación con los proveedores en franquicias de comida rápida*
}

\author{
Vílchez Gil, Alirio** \\ ** Licenciado en Contaduría Pública. Especialista en Costos, Docente-Investigador del \\ (CEE) de la Facultad de Ciencias Económicas y Sociales de LUZ. Maracaibo-Venezuela. \\ E-mail: gilvilchez2001@yahoo.com
}

\section{Resumen}

En la economía de hoy en día, las empresas que mueven inventarios necesitan mantener cada centavo invertido trabajando a un máximo de eficiencia. Dado que la inversión en inventarios representa un porcentaje elevado dentro de la inversión global de una empresa, la importancia de la administración de dicha inversión aumenta da a día. El objetivo primordial es analizar la gestión de los inventarios, en las franquicias de comida rápida y su relación con los proveedores, a partir de su evolución y elementos que lo caracterizan dado el éxito de este tipo de negocio. La metodología utilizada fue de tipo descriptiva y abarcó: Una revisión documental, entrevistas a operadores gerenciales del sector y a empleados del área objeto de investigación. Se llegó a una gran conclusión de que "EL SABER HACER" o "KNOW-HOW" o "SAVOIR FAIRE" como se le conoce en estos tres idiomas, es el elemento clave del éxito de la gestión del inventario y su relación con los proveedores, todo esto plasmado en Manuales.

Palabras clave: Franquicia, comida rápida, gestión de inventarios, proveedores, knowhow.

\section{Management of I nventories: Relations With Suppliers in Fast Food Chains}

\begin{abstract}
In the present economy, companies that move inventories need to maintain every penny invested at maximum efficiency. Since the investment in inventories represents an elevated percentage of the total investment of a company, it is increasingly important to manage that investment daily. The primary objective of this paper is to analyze the management of inventories in fast food chains, and the relationship of these chains with suppliers, given the evolution of this type of business, its characteristics and its success. The methodology employed was descriptive and included: documentary review, and interviews with management, operators and employees who manage inventories in this
\end{abstract}


sector. The conclusion of the study was that "KNOW HOW", "SAVOIR FAIRE" OR "EL SABER HACER" as it is called in these three languages, is the key element in the successful management of inventories and relations with suppliers, all of which is explained in the operational manuals of these companies.

Key words: Franchise, fast food, inventory management, suppliers, know-how.

Recibido: 01-10-22. Aceptado: 03-05-21

\section{Introducción}

Hoy en día uno de los aspectos más complejos de las empresas son sus Inventarios, que por lo general representan la mayor cuantía en el Capital de Trabajo de las empresas comerciales e industriales.

En el manejo de los inventarios se toman decisiones respecto a cuándo hacer pedidos, a quien hacerlos y en que cantidad. Todo se traduce en costos; y el principal de ellos es el costo de los artículos mismos, pero hay también otros como: almacenamiento, seguros, deterioro, interés sobre el dinero empleado, además, existen aquellos costos derivados de la no disponibilidad de un producto en un momento dado, lo que crea una imagen inaceptable y se corre el riesgo de perder un cliente.

El tiempo constituye uno de los factores más importantes en la relación entre el volumen de ventas promedio y el inventario promedio para un período dado, lo cual viene a representar la rotación de inventarios por lo que se hace necesario buscar la forma de manejarlos lo más eficientemente posible en función del tiempo, por ello surge la metodología de manejo de inventario justo a tiempo como la mejor herramienta que permite la disponibilidad del inventario para el momento en el cual se necesite y no acumularlo en un almacén. Otro aspecto a considerar en este mismo orden es maximizar la eficiencia en el manejo del inventario, por lo cual se debe tener una excelente relación con sus proveedores. De allí que, en lugar de tener varios proveedores de los cuales elegir, toda empresa debe desarrollar una política que le permita relacionarse con menos proveedores pero en todo caso los mejores de acuerdo al tipo de inventario que se maneje. De lo contrario se estaría corriendo el riesgo de incrementar los costos administrativos y sin lograr la calidad necesaria en el manejo del inventario.

Por otra parte no podemos dejar de mencionar a la Globalización como un fenómeno que responde a razones de cambios de orden tecnológico, de información, tipos de vida, de procesos sociales y a la estandarización de los procesos productivos en busca de la 
homogenización de las tareas que se realizan en una organización, mención particular a los Inventarios y su relación con los Proveedores en las Franquicias de comida rápida. También cabe mencionar a la Globalización como un proceso que ha estado incidiendo en gran medida en la economía global produciendo el surgimiento de nuevas formas de sociedad, de estado y pensamiento y sobre todo nuevas formas de Negocios. La gran alineación de las franquicias en el mundo, constituye una de las expresiones de la globalización; ellos ofrecen una filosofía de Trabajo, cuyo alcance se ha extendido por todo el mundo, lo que ha permitido expresar que ha sido un factor globalizante.

En el proceso de globalización la Integración de los mercados, la organización del trabajo, las nuevas condiciones de la competitividad y las estrategias empresariales como las alianzas, fusiones, adquisiciones, franquicias; han adquirido un lugar muy importante en los últimos años, modificándose como manifiesta Rojas (1999:179) "las teorías predominantes sobre comercio internacional“, con la finalidad de incrementar la eficiencia productiva reflejada en la productividad para manejar los inventarios y su relación con los proveedores, afectando a la significativamente competencia.

La franquicia tiene una forma particular de manejarse, obligando a todos los actores que intervienen en ella a conducirse de una forma estandarizada de acuerdo a unas reglas preestablecidas por una marca, lo que se conoce como Know How o en buen español Saber Hacer. En esta investigación la finalidad principal consiste en Saber Como se manejan los inventarios y su relación con los proveedores en el negocio de las franquicias de comida rápida.

Se puede afirmar que el manejo del inventario es un proceso de suma importancia y totalmente decisivo en la gestión de las empresas que mueven volúmenes importantes de inventarios. Presentándose la problemática que implica el costo financiero de mantener el inventario. Por lo cual el problema a resolver consiste en minimizar el inventario que se tenga en existencia ya que se ha podido demostrar la ventaja financiera de rotar más y mejor el inventario. De allí que oigamos decir a los ejecutivos financieros que el inventario sin moverse no agrega valor, en términos populares se dice "Barco parao no gana flete".

\section{Evolución de las franquicias de comida rápida}

Es necesario hacer un recorrido en el espacio y el tiempo para conocer cómo fue evolucionando la Franquicia de comida rápida ya que ello nos permitirá concluir cómo se manejó el inventario y cómo fue la relación con los proveedores en el espacio y el tiempo, objetivo principal de esta investigación. 
Es importante aclarar que hoy en día se ha querido presentar a la franquicia como un negocio novedoso e innovador. Sin embargo Barbadilla (2000:60) afirma que "los orígenes propiamente dichos de la franquicia también podemos encontrarlos en la jerarquía social de la Edad Media, que ha quedado recogida a través de los códigos mercantiles y el derecho consuetudinario de la época".

Desde la edad media época en que Barbadillo hace mención a la franquicia ésta se ha desarrollado de tal manera ha evolucionado de tal manera que permite resaltar hechos que confirman tal evolución, así podemos mencionar: La aparición del término Franquicia para distinguir las relaciones entre el rey y las alcaldías de las diferentes regiones del país en la Edad Media. Para principios del siglo XIX como lo afirma Barbadilla (2000) los acuerdos entre el rey y las alcaldías llegan al comercio inglés, producto de la necesidad en que se encontraban los pequeños empresarios al no contar con el capital necesario para poder mantener sus negocios, por lo cual se vieron en la necesidad de solicitar ayuda económica a las empresas más grandes que se encontraban en la misma línea de labor. Los pequeños empresarios tenían la obligación de adquirir toda la mercancía de aquella empresa que les había prestado ayuda económica. Tenían la libertad de administrar el negocio a su manera, y garantizando una distribución segura de los productos.

Para 1898 el crecimiento de la franquicia en Estados Unidos se desarrolló por las leyes que buscaban impedir el monopolio. Como sistema de distribución se fomentó, básicamente en la industria automotriz, cuando la General Motors y Henry Ford la utilizaron como medio de distribución para comercializar sus automóviles. Este tipo de franquicias de acuerdo Barbadilla (2000: 61) surge cuando "se cede el derecho al uso de una marca y la distribución de un producto, son denominadas en Estados Unidos Trade name and product Franchises “.

A partir del siglo $\mathrm{XX}$, la franquicia se fomenta en otros sectores de Estados Unidos como en Farmacias y cosméticos con un contenido diferente, que según Diez et al. (1998:3) “designaba un nuevo sistema de distribución basado en la integración parcial en una entidad económica de apariencia única, de comerciantes-empresarios independientes que han adquirido de un jefe de filas, y a cambio de una remuneración, el privilegio de explotar localmente sus sistemas de comercialización". Y para el siglo XX, en la franquicia no sólo se cedía el derecho de distribuir el producto, sino que se empieza a transmitir al franquiciado el método operativo de producción, visualizándose desde ese momento lo que conocemos hoy en día como know how o saber hacer.

En esta misma época ( siglo XX) empezaron a surgir las franquicias de comida rápida 
reconocidas mundialmente como: McDonald's, Kentucky Fried Chiquen, entre otras. Vista la evolución de las franquicias, podemos afirmar que es la década de los años ochenta donde se presenta la mayor expansión de las mismas. Al instalarse en Pekín y Moscú una franquicia de comida rápida como McDonald's en países con culturas tan arraigadas y diferentes a la norteamericana, lo que le permitió a Barbadilla (2000:61) afirmar "en los cinco continentes su éxito como sistema de comercio asociado". Se enrumba así la franquicia hacia la globalización económica al traspasar fronteras y multiplicar los negocios en todo el globo terráqueo, fundamento básico de la expansión de la franquicia como estrategia empresarial. Así lo afirman varios autores además de Barbadilla, Di Costanzo y otros (1997); Diez y Galan (1998) entre otros, al expresar que las franquicias se han convertido en un ejemplo relevante de este tipo de inversión. La expansión de la franquicia ha sido espectacular en los últimos años, convirtiéndose en uno de los vehículos más poderosos para forjar la internacionalización creciente de las actividades comerciales. Todo esto permite que aparezca la franquicia como una alternativa de inversión.

\section{Características de las franquicias de comida rápida}

Diez y Galán (1998:4) afirmar que la franquicia es “un sistema de cooperación entre empresas diferentes, pero ligadas por un contrato, en virtud del cual una de ellas -la franquiciadora - otorga a la otra (u otras), denominadas franquiciadas, a cambio de unas contraprestaciones (pagos), el derecho a explotar una marca y/o una fórmula comercial materializada en unos signos distintivos, asegurándole al mismo tiempo la ayuda técnica y los servicios regulares necesarios destinados a facilitar dicha explotación".

Algunos de los objetivos de la franquicia como estrategia empresarial, desde la visión del franquiciante, permiten visualizar las características siguientes que la definen como negocio franquiciado: 1) Expandir la empresa en el mercado; 2) Buscar socios; 3) Establecer un sistema de cooperación; 4) Compartir riesgos; 5) Ampliar la capacidad financiera; 6) Aperturar mercados para mejorar el posicionamiento de la empresa a nivel competitivo y 7) Asegurar un lugar en la economía globalizada.

Las características de las franquicias y en especial las de comida rápida empírico y de las observaciones en diferentes negocios de franquicias. De acuerdo a como lo afirman Useche et al (2001:119), son: “Establecimiento de un sistema de cooperación contractual. Relación entre dos empresas financieramente independientes. El objetivo de una (el franquiciante) es expandir el negocio mediante el otorgamiento del derecho de explotar un bien o servicio, y el de el franquiciado, realizar una inversión con el menor riesgo posible 
que genere beneficios económicos rentables a cambio de una contraprestación económica".

A continuación los elementos que constituyen una franquicia de comida rápida y a través de ellos las características que la definen como tal y que permiten diferenciarlas de otro tipo de negocio:

\section{Productos ofertados por franquicias}

Según Diez y Galán $(1998: 35,36)$ “las características relativas al producto ofertado se centran en los tres puntos siguientes: diferenciación, competitividad y surtido. La diferenciación es una de las circunstancias que aumenta las posibilidades de éxito de la franquicia. Esto se produce cuando el producto o servicio se diferencia claramente de los competidores, es decir, está dotado de una fuerte personalidad u originalidad".

Además de diferente, el producto debe ser competitivo, bien en el precio, en la calidad o en la relación calidad-precio. Un aspecto relevante se produce cuando las ventajas competitivas referidas, tecnológicas o de innovación, son inimitables o lo que es lo mismo, no pueden ser copiadas por los competidores.

Respecto al surtido, las condiciones favorables pasan porque la gama de productos ofertados por un punto de venta, sea homogénea, completa y especializada. Estas tres características están perfectamente interrelacionadas. Además la franquicia posee una característica básica como es su especialización y homogeneidad en cuanto al surtido. Es decir, el surtido debe ser completo, deberá contar con todos los productos complementarios y servicios accesorios que requieran los clientes que demandan dichos productos, haciendo obvio que la especialización y homogeneidad del surtido determina la rentabilidad del negocio franquiciado.

En las franquicias internacionales de comida rápida en Maracaibo, son claras y evidentes las características del bien o servicio ofertado: condiciones de diferenciación, competitividad y surtido y en cuanto a éste la especialización y homogeneidad. Según información que maneja la Cámara Nacional de Franquicias en Venezuela, las franquicias de comida rápida el primer lugar lo ocupa McDonal's y el segundo Wendy's por lo que considero necesario contrastar sus productos. En ambos casos siempre existen productos ofertados que se diferencian, y que como estrategia de mercadeo buscan captar la preferencia del público consumidor.

Como se puede observar en las listas de productos ofertados por las dos compañías 
existe una amplia variedad .Visualizase así claramente las características señaladas por Diez y Galán (1998) en cuanto al surtido que es homogéneo, completo y especializado. Sin Embargo existe un monitoreo permanente entre las compañías, lo que ha permitido observar que se han dado situaciones como la siguiente Wendy's sacó al mercado hamburguesa con tocinetas de gran aceptación por parte del público consumidor. McDonal's procedió entonces a ofrecer una hamburguesa con tocineta buscando ser competitivo en cuanto a la oferta de productos, por lo cual la diferenciación del producto se ha venido perdiendo poco a poco.

En cuanto a la relación calidad-precio, se mantiene muy reñida por lo que la competitividad se hace en cuanto a calidad del servicio y rapidez del mismo, así como las promociones que ofrecen de sus productos. Por ejemplo McDonal's publicita su promoción "Mc Ahorro" con precios especiales de lunes a jueves. Wendy's por su parte ofrece especialidades en ensaladas frescas todo el día y todos los días.

\section{La marca un signo distintivo}

Murphy y Rowe citado por Diez y Galán (1998) Plantean que las marcas poseen diferentes utilidades: Identifican un producto, servicio o compañía, sirven para diferenciar productos o servicios, representan un valor añadido para la empresa y constituyen una propiedad legal importante.

Según los autores la valoración de una marca, desde la perspectiva de una red franquiciada, es muy importante. Generalmente, la importancia y el atractivo del franquiciador está en función de la marca y de los productos o servicios inherentes a la misma". Son relevante la propiedad legal de la marca, la notoriedad y la imagen de la misma; el grado de notoriedad de una marca se logra a través de los medios de comunicación lo que permite darla a conocer, ya que en una franquicia desconocida o poco conocida, su valor es más reducido, por lo cual existirán menos candidatos que la demanden, y el dueño de la franquicia sé encontrará con menos poder de negociación y las posibilidades de éxito serán menores.

La marca, es una de las característica de las franquicias que se conoce en el Derecho Mercantil como signos distintivos de una empresa, los cuales vienen a ser una de las mayores ventajas de la misma; el franquiciado pasa a disponer de una marca acreditada, así como de los emblemas, etc.; del franquiciador. Según Sánchez citado por Diez y Galán (1998: 31) “Los signos distintivos de una empresa son los instrumentos utilizados para la comercialización y diferenciación de los productos o servicios, para el desarrollo y protección de su empresa y la conservación de la clientela". Para Dí costanzo et al (1998: 
11) "una marca bien posicionada ayuda a la franquicia a ganar clientes".

\section{Saber Hacer}

Para nadie es un secreto y así se ha podido comprobar a través de las publicaciones de los Medios y en nuestra investigación, que uno de los factores de éxito de las franquicias lo constituye la marca. Sin embargo es de suma importancia destacar que en las franquicias de comida rápida además de la marca, el "saber hacer" o know how como se le conoce en la literatura Norteamericana viene a constituir ese toque garantizador de éxito en el manejo de las franquicias. De allí que Diez y Galán (1998:33) expresen que "el conjunto de conocimientos que comprende el saber hacer es difícil de precisar de forma individual. Comprende aspectos como el surtido adecuado, publicidad adecuada, técnicas adecuadas, buena gestión, correcto aprovisionamiento, etc." También define Pérez, M. Citado por Diez y Galán (1998:32) "el saber hacer se define como un conjunto de conocimientos empíricos que no pueden ser presentados con precisión de una forma aislada, pero que cuando son puestos en práctica de una manera determinada, basada en la experiencia, facilitan al que los aplica la aptitud para obtener un resultado, que de otra forma no hubiera podido esperarse con la exactitud necesaria en la eficacia comercial". De hecho en todas las áreas de la franquicia se aplica el saber hacer y el manejo del inventario y la relación con los proveedores no corresponden a ello.

La transmisión del saber hacer se hace mediante manuales cuyo manejo requiere un tiempo más o menos extendido, en función de su contenido. Según Pérez citado por Diez y Galán (1998:33) "algunos franquiciadores estiman que la transmisión del saber hacer requiere un período que oscila entre tres y diez años." Sin embargo es conveniente hacer la salvedad que en las franquicias de comida rápida la transmisión del saber hacer actualmente requiere mucho menos tiempo debido a que constantemente se ésta en una práctica de observación y actualización de los manuales. La rotación del personal se controla de manera que siempre haya personal con experiencia que ayude a formar al empleado nuevo, estimándose el período de entrenamiento en poco más o menos seis meses.

En los Manuales de la Franquicia se plasman por escrito los conocimientos sobre las estructuras de la Empresa, las técnicas de mercadeo, los planes financieros, contables y dentro de todo esto indican al detalle todos los pasos a seguir en cada una de las acciones a emprender para que el franquiciado sepa cómo llevar a cabo las directrices del franquiciador. Al respecto Diez y Galán (1998:32) expresan “la estandarización no tiene que ser sinónimo de rigidez. Es aconsejable que el franquiciado tenga un cierto grado de 
autonomía, siempre dentro del respeto a las políticas comunes a la cadena, de forma que pueda adecuar su negocio al mercado en el que está ejerciendo su actividad, I gualmente, dotarle de la posibilidad de desarrollar sus capacidades, de reaccionar frente a la competencia, etc.".

A los franquiciados se les hace firmar en el contrato una cláusula de confidencialidad en la que se comprometen a no divulgar el Know-How durante la duración del contrato y una serie de años con posterioridad a la terminación del mismo. Igualmente esta cláusula de confidencialidad se le hace firmar a todos los empleados por cuanto ellos reciben entrenamiento en todas las áreas del negocio.

\section{Transmisión del saber hacer}

El proceso de Globalización de la economía y la competitividad de todos los sectores tanto en los mercados nacionales como internacionales, demanda innovación, creatividad y excelencia de investigación en los sectores. La Franquicia no escapa al proceso de Globalización ni a la competitividad, como se ha observar a través de su evolución y características. Dentro de las características se puede hacer mención especial a la forma de cómo se transmiten los conocimientos al franquiciado y lo que en este mundo de negocios se ha llamado el "saber hacer" de las Franquicias. Estos conocimientos habitualmente se materializan en Manuales que recogen la fórmula de éxito a través de la cual se ha conseguido que una empresa se posicione en su mercado de forma apropiada y competitiva.

Según Dí costanzo et at (1998: 76) “La estandarización del producto y servicio que ofrece la unidad franquiciada determina su posicionamiento en el mercado, la satisfacción del cliente y la uniformidad del servicio. Por ello, los manuales de operación son un elemento esencial para el desarrollo del sistema de franquicias". Razón por la cual deben ser desarrollados cuidadosamente para que el franquiciado tenga en él una referencia regular y confiable donde poder apoyarse.

Franquiciar un tipo de negocio es la reiteración de su éxito comercial o lo que es lo mismo no podemos franquiciar un negocio que no haya sido exitoso, mediante la transmisión de experiencias sobre el "saber hacer" contrastadas a través de la explotación y rentabilización de una o varias unidades operativas.

El saber hacer viene a ser el conjunto de experiencias prácticas en las empresas en cuanto a los métodos de fabricación, procedimientos comerciales, logísticos, financieros, manejo de personal, manejo administrativo, manejo del inventario, relación con los 
proveedores y en fin en cada una de las áreas de una organización donde existan centros de responsabilidades en donde día a día se están tomando decisiones que al fin y a cabo afectan la rentabilidad de la organización. La trasmisión de conocimientos la hace el franquiciador al franquiciado a través de lo que habitualmente se conoce como paquete de franquicia y que podemos considerar integrado por cuatro grandes áreas específicamente definidas: informativa, operativa, contractual y formativa. El presente artículo destaca la importancia del área operativa en cuanto al manejo y relación con los proveedores todo ello descrito en el Manual operativo de Franquicia.

De hecho, el saber hacer se ha asociado como una de las grandes ventajas de la Franquicia donde el inversionista (Franquiciado) no requiere tener experiencia sobre el negocio, lo que permite ampliar el número de los posibles interesados. Quedando claro que es el franquiciador quien aporta el saber hacer o know-how. A demás se recomienda que el candidato potencial a franquiciado no tenga conocimientos acerca del negocio a franquiciar ya que podría presentarse falta de apego al saber hacer impartido por el franquiciador.

El franquiciador es el sujeto que debe asumir las responsabilidades de entrenar e innovar, ya que es quien conoce el negocio dueño del saber hacer y por lo tanto puede traspasar la información pertinente y su permanente actualización.

Una trasmisión efectiva del saber hacer es aquella que permita al franquiciado disponer de una información documentada a la que pueda remitirse en un momento dado para efectuar una consulta sin dificultad alguna; la misma se encuentra en los Manuales de Negocio, en donde queda recogida la experiencia y saber hacer del franquiciador, así tenemos: Manual de Normas Gráficas e Imagen Corporativa, Manual de adecuación y decoración del local, Manual operativos de franquicia, Manual de estructura empresarial, Manual de concepto de negocio, Manual de gestión comercial, Manual de procedimiento, Manual administrativo, Manual de control y supervisión, Manual económico y financiero y Manual técnico de productos y servicios. Además se incluye un Manual de suma importancia dentro del negocio de las Franquicias Ilamado Manual del área Formativa, el cual esta integrado por los diferentes métodos para la formación de los empleados.

Considerando que la Franquicia basa su éxito en la reproducción de las prácticas comerciales, operativas, económicas y de dirección-gestión de un negocio, el franquiciador debe disponer de los soportes documentados adecuadamente para la trasmisión a los franquiciados de su "SABER HACER".

Según Diez y Galán (1998:34,35) “cuando decimos que el Know-how debe ser sustancial 
estamos indicando que debe incluir una información relevante para la venta de productos o la prestación de servicios a los usuarios finales, y de forma particular, en la presentación de los productos para la venta, la transformación de productos en relación con la prestación de servicios, las relaciones con la clientela y la gestión administrativa y financiera" y así mismo la relación con sus proveedores, que influye significativamente en el costo de manejar los inventarios y define la mejor forma de manejarse con los proveedores, en lo que se ha dado en llamar la cadena de valores.

El saber hacer está plasmado en cada uno de los manuales enunciados anteriormente, de inmediato se pasará a definir de una manera general cada uno de ellos haciendo hincapié en el Manual técnico de productos y servicios ya que es en este aspecto donde se centra el objetivo principal de esta investigación:

\section{Manual de normas gráficas e imagen corporativa}

En éste se recogen todas las políticas establecidas en cuanto a la imagen de la Franquicia como: presentación de logotipos, especificaciones tipográficas y de color; material publicitario y promocional, papelería, elementos de transporte, rótulos de establecimiento, equipamientos de empleados, entre otros.

\section{Manual de adecuación y decoración del local}

Este manual indicará los diferentes aspectos de adecuación, decoración y equipamiento de un local de acuerdo al modelo tipo de la cadena especificado en el contrato de franquicia, considerando: distribución de interiores, equipamiento, decoración interior y exterior, planos de fachada y planta, presupuesto estimado, etc., todo esto en función de estudios de tiempo y movimientos considerando las necesidades planteadas y al menor costo posible.

\section{Manuales de operativos de franquicia}

Facilitan al franquiciado los conocimientos necesarios para la correcta explotación del negocio.

\section{Manual de estructura empresarial}

Incluye el organigrama de la central de franquicia y da a conocer las funciones de los diferentes departamentos y secciones de la misma.

\section{Manual de concepto de negocio}


Especifican los parámetros que definen e identifican el concepto de negocio sobre el cual se fundamenta la franquicia: perfil del cliente, demanda potencial, definición de productos y servicios, características del local y del mercado de implantación, política comercial, asistencia y servicios al franquiciado, obligaciones del franquiciado.

\section{Manual de gestión comercial}

En este manual se tratan aspectos como: mercadeo y publicidad, políticas de precios, técnicas y sistemas de ventas, motivaciones del cliente, elementos diferenciadores del producto o servicio, medios publicitarios y promocionales.

\section{Manual de procedimientos}

Criterios y requisitos de implantación, delimitación de la zona de exclusividad, gestiones previas a la apertura, exclusividad de suministro, stock de seguridad, condiciones de pedido y entrega, consideraciones de la oferta. También incluye una enumeración de los diferentes puestos de trabajo del centro franquiciado, así como la definición de funciones y objetivos, técnicas de reclutamiento de personal, horarios de apertura y cierre, etc.

\section{Manual administrativo}

Informar al franquiciado respecto a procedimientos contables, informes analíticos de gestión, programas de computación. Todo esto le facilita al franquiciador analizar la calidad de gestión y trayectoria de ventas del centro franquiciado.

\section{Manual de control y supervisión}

Determinadas las técnicas y métodos de inspección en relación a la calidad de la gestión, incluyendo el test de control y supervisión a aplicar por personal técnico del franquiciador.

\section{Manual económico y financiero}

Incluyen los presupuestos económicos y planes financieros adaptados a las circunstancias particulares de cada una de las tiendas franquiciadas. Estos presupuestos se elaboran con una proyección para tres años y cada mes para el primer período de operaciones. De esta manera y en función de los resultados de la tienda franquiciada se podrá conocer su calidad de gestión, analizar las posibles desviaciones con respecto a los objetivos iniciales y tomar decisiones o correctivos oportunos para la consecución de los mismos. 


\section{Manual técnico de productos y servicios}

Facilita al franquiciado una presentación de los productos y servicios que integrarán su oferta indicando las principales características técnicas de todos ellos como: pesos, colores, tallas, materiales componentes, técnicas de elaboración y presentación, en fin todos aquellas formas de manejo tanto en el inventario como con la manera de proveerse sus materiales con el objetivo de minimizar sus costos y ser los más eficiente posible y en el menor tiempo posible. De allí la importancia de este manual para el tema de esta investigación.

También se emplean en este manual las obligaciones relacionadas con los productos en cuanto a vender o utilizar, en el marco de la prestación de servicios, productos que cumplan las especificaciones mínimas de calidad establecidas por el franquiciador, pues de lo contrario podría perjudicarse la imagen de la calidad de productos ofrecido por la red franquiciada.

\section{El inventario de mercancías}

Es obligación del franquiciado vender o utilizar, en el marco de la prestación de servicios, productos fabricados exclusivamente por el franquiciador o por terceros designados por éste.

El franquiciado tiene la obligación de vender los productos sólo a los usuarios finales del negocio, y a revendedores pertenecientes a otros canales aprovisionados por el fabricante de dichos productos o con su consentimiento. Debe el franquiciado obrar con la máxima diligencia en la venta de productos o en la prestación de los servicios; ofrecer a la venta una gama mínima de productos, facturar un monto mínimo establecido por el franquiciante, planificar de antemano sus pedidos, mantener unas existencias mínimas y prestar el servicio de asistencia a la clientela y de garantía.

El éxito de las cadenas de franquicias depende, en gran medida, de la sinergia que se establezca entre franquiciador y franquiciados. En efecto, sólo a través de un sistema de colaboración efectiva entre los miembros de la cadena puede alcanzarse y mantenerse un nivel de competitividad cónsono con las exigencias del mercado.

Con respecto al inventario de material directo utilizado para la preparación del producto final existe una rotación de alta frecuencia, debido a que se trabaja con productos de consumo masivo; no olvidemos que en las franquicias de comida rápida se trata de productos perecederos cuya descomposición es muy rápida, de allí que los materiales 
Ileguen al punto de transformación y venta, de manera interdiaria. Todo esto define la importancia en el control de calidad en el proceso administrativo, lo cual es esencial para implantar y operar una unidad franquiciada.

Una de las ventajas en la utilización de los manuales de operación es la estandarización, la cual puede considerarse como el objetivo principal y más importante de los manuales, ya que le permiten al franquiciado repetir el producto y el proceso del sistema de franquicia a la perfección.

Los manuales describen por volumen los diferentes inventarios necesarios para el arranque y operación de la franquicia, definiendo además la manera de manejar los diferentes materiales en cada una de las tareas a realizar y la forma cómo aprovisionarse de ellos.

A pesar de que existen cláusulas de confidencialidad en el manejo de las franquicias, que obstaculizaron el acercamiento más confiable a la información se pudo observar lo siguiente:

1. Existencia de un manual técnico de productos y servicios que facilita la gestión y manejo de los mismos.

2. Los materiales se piden una vez a la semana al centro de aprovisionamiento respectivo.

3. Son propiedad del franquiciador los centros y son jurídicamente diferentes de las tiendas franquiciadas; en el caso de las tiendas Mc Donal's, es la compañía McKey, ubicada en la ciudad de Valencia, la que resuelve los pedidos, cuando se presenta una falla de materiales antes de la fecha de suministros.

4. Todos los días se revisan los inventarios, esencialmente los productos críticos que son aquellos perecederos, con el fin de tener control de los materiales que se están consumiendo y saber si existe armonía y ritmo en las entradas, procesos y salidas, este procedimiento proporciona información para saber cuánto hay que abastecerse y, también permite conocer cómo se está consumiendo, qué tanta eficiencia tienen y cuánto desperdicio se esta generando. También se realiza un inventario semanal, que constituye la base para hacer los nuevos pedidos; para determinar el abastecimiento de los insumos en general se hace un inventario mensual, el cual incluye bienes perecederos como carnes, lechuga, papa, pan, entre otros, y no perecederos como servilletas, vasos plásticos, plásticos de cartón, etc. y productos de limpieza los cuales son importados. 
5. Respecto al almacenamiento, las franquicias de comida cuentan con un depósito donde se almacenan productos secos, un depósito de refrigerio para las verduras y un congelador para carnes y pollos. Todos los materiales tienen una durabilidad medida en días y horas en función de la calidad del producto ofrecido.

6. Las franquicias de comida rápida no realizan inventarios de productos terminados por cuanto estos son preparados al momento, cuando lo requiera el cliente; sí por cualquier causa llega a quedar algún producto, es desechado por en atención de la calidad.

7. Se efectúa un monitoreo constante de los productos vendidos lo que permite ser competitivo entre las diferentes franquicias de comida rápida. Quincenal o mensualmente se efectúa un estudio de la demanda a fin de poder conocer cuáles fueron las variaciones de las ventas de productos y pronosticar las nuevas y posibles ventas. Con esa información se establecen los estándares en cuanto al tamaño, composición, empaque y presentación de los productos para lograr un control cuantificable de los mismos.

8. A todo individuo que ingresa a una franquicia de comida rápida para trabajar se le aplica un plan de entrenamiento que dura aproximadamente 45 días y durante este período el candidato pasa por todas las actividades desarrollando así sus habilidades y destrezas.

9. El tiempo estándar establecido para la preparación del servicio es uno de los elementos que define el éxito de la franquicia e incide en la administración de los inventarios, los cuales son diariamente monitoreados; para controlar el agotamiento del inventario, se aplica el índice de rotación de inventario el cual refleja cuán a menudo los pedidos no son cumplidos como consecuencia de no tener materiales en inventario, Si el índice es bajo significa un buen servicio al clientes, ya que sus necesidades pueden ser satisfechas con el inventario disponibles. En la franquicia de comida rápida el análisis de la rotación del inventario refleja el número de veces que el nivel de inventarios es vendido en un período. Esta información es útil en la identificación de partidas de lento o rápido movimiento, comparando el rendimiento del presente con el pasado e identificando problemas de precios. Al respecto se observó un alto índice de rotación que significa que se está trabajando el inventario en una forma fuerte, lo que permite obtener un elevado retorno de la inversión efectuada en inventarios. Sin embargo debe reconocerse que habitualmente en las tiendas de comida rápida la rotación de inventarios es rápida.

10. Una meta clave en la administración de inventarios es maximizar la rotación mientras se minimiza el agotamiento que es según Polímeni et al (1994:3). El factor más importante de los procesos de producción de manufactura para disminuir el tiempo "sin 
valor agregado" que se asocia a la terminación de un producto y, por lo tanto, para reducir el nivel de inventarios. Esta es la filosofía implícita en la estrategia de manufactura conocida como producción justo a tiempo.

11. Otro factor clave en éste tipo de negocio es la determinación de los niveles de inventarios apropiados; para ello es necesario pronosticar la demanda esperada de cada producto en un período futuro. Las franquicias de comida rápida utilizan métodos estadísticos simples para su cálculo producto por producto a través del computador y actualizándolos frecuentemente. Se emplea un alto grado de criterio y conocimiento del negocio en la evaluación de la razonabilidad de los resultados del pronóstico.

12. El sistema de registro del inventario que se utiliza es el Perpetuo o Permanente, que es aquel en donde el negocio mantiene un registro continuo de cada artículo del inventario, de esta manera pueden mostrar las existencias disponibles en cualquier momento, además son útiles para preparar los Estados Financieros mensuales o en cualquier período.

13. En cuanto a la valuación del inventario se utiliza el método P.E.P.S. (Primero en entrar, Primero en salir). Este método permite manejar el tipo de inventario que es perecedero y tener un mejor control de las existencias.

Tan importante es saber manejar los inventarios como relacionarse con los proveedores en las franquicias de comida rápida aspectos estos que garantizan el éxito del negocio.

En las estructuras de costos de los negocios actualmente se observa según Hay (1995: 132) que "un 70\% son los materiales comprados, un 10\% la mano de obra y un $20 \%$ los gastos generales. Esto significa que el departamento de compras gasta más del doble de dinero que todas las demás funciones de la empresa sumadas. Una reducción de por ejemplo del 5 por ciento en los precios de compra tendría repercusión sobre las utilidades finales", De mayor importe que si se hiciera en la mano de obra o en los gastos generales. Las franquicias de comida rápida no escapan a la observación de Hay ya que se analizaron algunos Estados Financieros y se observó la misma tendencia.

Pero es importante destacar que los costos no son el único aspecto en que los proveedores influyen de manera determinante en los resultados de las empresas. Así podemos destacar que de la calidad de sus materiales depende el éxito o fracaso de un producto, sumado a la calidad, el tiempo de despacho es un factor necesario para dar repuesta a la demanda de la clientela, el cual en la mayoría de los casos depende más de los tiempos de producción de los proveedores que de la empresa. 
Como afirma Hay (1995: 31) "en una secuencia cualquiera de hechos o de operaciones que tenga equilibrio-, sincronización y flujo incluirá poca o ninguna actividad de desperdicio"- Hay (1995:33) también expone que "una vez que la empresa cuenta con una fuente de suministro y un precio acordado, suceden varias cosas en el proceso de compra que no agregan valor al producto. Una orden de compra no agrega valor al producto. Una enmienda a la orden de compra no agrega valor. Las remisiones y los informes de recibo y las facturas no agregan valor. Sacar algo de un camión y colocarlo en un muelle central de recepción no agrega valor, como tampoco el traslado a una zona de espera. La inspección no agrega valor, como tampoco su colocación en un depósito. Los recuentos no agregan valor. Sacar el artículo de un recipiente grande y colocarlo en uno pequeño no agrega valor. Trasladarlo al punto donde se va a utilizar no agrega valor. Los costos de transporte no agregan valor. Ninguna de estas cosas agregan valor y, sin embargo forman parte de los mecanismos de control entre comprador y vendedor".

En las franquicias de comidas rápidas en lo que respecta a sus proveedores, las compras se manejan bajo la filosofía de la técnica japonesa justo a tiempo, pero con una particularidad muy propia de este tipo de negocio, la cual consiste en que es el franquiciante basado en la fuerza legal que le otorga el contrato que firma con el franquiciado, quien maneja todo lo relacionado con las compras. Así esta definido en el Manual técnico de productos y servicios descrito en puntos anteriores.

\section{Conclusiones}

Dada la expansión de la franquicia como estrategia de negocio y su observada flexibilidad en cuanto a sus técnicas, procedimientos y en fin en todo su manejo, ellas las franquicias son totalmente rígidas, no otorgan autonomía al franquiciado debido a la exigencia que supone la identificación del "saber hacer" de las franquicias. Estos conocimientos "secretos" habitualmente se identifican y plasman a través de los Manuales de negocio que recogen la fórmula de éxito, la cual ha permitido que una empresa se posicione de manera adecuada.

En consecuencia podemos afirmar que el inventario de materiales y su relación con los proveedores en cuanto a su manejo las decisiones se toman en función de lo que indiquen los Manuales. En especial el Manual técnico de productos y servicios.

Sin lugar a dudas, la observación y el análisis de la utilidad potencial de los Manuales, Saber Hacer o Know How como también se le conoce en las franquicias estudiadas, viene a constituir una profunda y segura evidencia en cuanto a que franquiciar un cierto concepto de negocio es la reiteración de su éxito comercial, todo esto a partir del análisis 
realizado y con el apoyo de fuentes bibliográficas especializadas.

Podemos afirmar que la filosofía de manejo de inventarios sobre la cual trabajan las Franquicias de comida rápida es justo a tiempo, herramienta esta como la mejor que permite la disponibilidad del inventario para el momento en el cual se necesite y no para acumularlo en un almacén.

El inventario es valuado según el método P.E.P.S. (Primeras en entrar, Primeras en salir), el cual consiste en valuar los inventarios de materias primas de acuerdo al orden de llegada, el manejo de la valuación del inventario de materia prima es responsabilidad del subgerente de la franquicia. El control se lleva a diario principalmente en los productos críticos entendiéndose estos como aquellos productos perecederos que son de fácil descomposición en poco tiempo cabe destacar entre ellos: El pollo empanizado, las carnes, las papas entre otros.

Por último en cuanto a la relación que tiene la Franquicia de comida rápida con sus proveedores existe un Manual en cada franquicia que establece todo lo referente a los pedidos en cuanto a proveedores. Por consiguiente la relación de las franquicias con sus proveedores es muy distanciada, es decir, los proveedores tienen muy poca comunicación con el franquiciado, esto se debe a que ya toda esta establecida en los Manuales que planifica el franquiciador.

* El presente artículo forma parte del proyecto de investigación titulado “Manejo del inventario relación con los proveedores en franquicias de comida rápida" adscrito al Programa de Modernización Empresarial de la Universidad del Zulia (LUZ).

\section{Referencias Bibliográficas}

1. Barbadilla, Manuel (2000), La Franquicia paso a paso: Guía Práctica sobre el Sistema de Mayor Éxito en los Últimos Años. Editor Barbadilla Asociados Consultores. Primera Edición. España.

2. Di Costanzo, Juan; Vilalta, Alejandra; Cárdenas, Donato (1997), Desarrollo de Sistemas de Franquicias. Mc Graw Hill. México.

3. Diez, Carlos y Galán, José (1998), Práctica de la Franquicia. Mc Graw Hill. España. 
4. Hay, Edward J. (1995), Justo a Tiempo. Grupo Editorial Norma. Octava Reimpresión, Colombia. Polimeni, RALPH, Fabozzi, Frank, Adelberg, Arthur y Kole, Michael (1994), Contabilidad de Costos. Tercera Edición. McGRAW-HILL. México.

5. Rojas, Claudio (1999), Internalización y Acción Pública. La complejización de la Organización del Trabajo en la Estrategia de Desarrollo Chilena en Trabajo y Empresa: entre dos siglos. Montero Cecilia, Alburqueque Mario Jaime Ensignia. Editores Nueva Sociedad Venezuela.

6. Useche, María. Añez, Carmen, y Boscán, Roberto (2001), “La franquicia como estrategia empresarial en el marco de la globalización". Revista Venezolana de Ciencias Sociales. Vol. 5 No. 1. Venezuela, Universidad Rafael María Baralt, pp. 111-130. 